\title{
Relationship between Inertial Features of the Upper Extremity and Simple Reaction Time in Boys and Girls Aged 17-181
}

\author{
B. I. Gutnik, N. B. Pankova, M. Yu. Karganov, and D. Nash \\ Received February 16, 2013
}

\begin{abstract}
The latent period of visual sensor-motor reaction depends, in part, on the sensory and integrative processes in the brain, but is also influenced by the rate of the muscle contraction. There is no clear evidence in the literature whether the rotational inertia of segments of limbs has any direct effect on the reaction time. The aim of our study was to identify this relationship. The study involved 566 right handed students aged 1617 of both genders beginning their post puberty period. Reaction time was measured during experimental adduction of the forearm and hand, using a special rotating handle and lever connected to a computer that recorded the reaction time $(\sim 1 \mathrm{~ms})$.

Calculations of the rotational inertia were carried out using regression models by Zatsiorsky and other authors. Each gender group was divided into three subgroups: with high, medium and low values of rotational inertia. It was found that individuals with high values of rotational inertia of forearm and wrist demonstrated significantly longer reaction times. This pattern was apparent in both gender groups. Although males illustrated greater values of rotational inertia than females they demonstrated relatively shorter reaction times. This contradiction can be explained by greater muscle power of young men. We recommend taking into account the amount of rotational inertia of the responsive segment in all kinds of research which require measurement of reaction time.
\end{abstract}

Keywords: rotational inertia, reaction time.

DOI: $10.1134 / \mathrm{S} 0362119714020078$

\section{INTRODUCTION}

Quickness of reaction to external stimuli is an important and necessary attribute for survival. One of the components of this response involves the latent period of simple sensor-motor reaction that is often viewed to be the result of integrative brain function [1]. Results of studies of the reaction time (RT), expressed as the interval between the time of signal detection and the beginning of motor response, are widely used in various fields of science and practice [2-4]. Researchers have identified several important stages of percolation of any sensor reaction: a) sensation of the stimulus, b) decision-making process, and c) the implementation of motor actions [4-8]. The influence of the motor component in the implementation of a simple motor response and reaction time, noted by the abovementioned authors, is associated mainly with the type of nervous system rather than biomechanical and anthropometric characteristics of participants. Motor action itself has an essential influence on RT. It has long been established that the amplitude of the electromyogram has an inverse correlation with simple reaction time [9]. The period of muscular mechanical contraction is an important element which may delay reaction time [10] and according to Bernstein [1] there

\footnotetext{
${ }^{1}$ The article was translated by the authors.
}

is no simple linkage between motor neuronal output and movement.

External forces, within the periphery of the body and in the environment, may also affect reactions whereby the same neural output can generate different behavioral effects. Thus the eventual effect of neural outputs could be determined by a large peripheral influence. Bernstein's [1] theory implies that limb shape and current physical properties of contracted musculature distort motor output. It is also known that motor output involves inertial forces, which often impede the implementation of movement [11-13]. These forces, in turn, depend on the mass and length of the driving segments, as well as the localization of the centers of mass of the reacting kinematic chain. Masses and lengths of reacting segments may affect reaction time [14-18]. It has been proved that the duration of the simple sensor-motor reaction performed by pressing a button with the index finger, a segment with small mass, is significantly reduced compared with the reaction time of large responding segments or the total body, for example during a jump or sprint [19-24].

From a biomechanical perspective the masses and lengths of the reacting segments represent their inertial features and should be treated as peripheral elements of the motor system [25]. Specifically, a relationship to rotational inertia can be considered, 
because all movement in the joints is rotary. Some authors studied the influence of rotational inertia of the reacting segments on the duration of motor reaction. For example, Anson [26] artificially increased the weight of the proximal and distal segments of tested limbs. He found some delay in reaction time corresponding with increasing rotational inertia of the reacting segment and vice versa. The main shortcoming of his study was that the experimental gravitational conditions for the test were very artificial and the motor program(s) selected for this new motor action had not been properly adapted to the new environmental force conditions.

Other researchers have increasingly paid attention only to the length of the limbs or total body height [14, 17]. They concluded that participants with short stature and relatively short upper limbs react to simple stimuli more quickly, and vice versa. However, it must be remembered that these data are indirectly related to the inertial features of the upper extremities, because their lengths may only partially reflect these features. For the same reason, studies which show the influence of body mass index on reaction time $[16,27,28]$ may not reflect the true biomechanical cause of slowing of motor reactions in some tall and large people. Some researchers noted that people with higher mass had longer reaction time, but explanations of their results were linked to only purely neural factors, such as distortion of sensory and proprioceptive signals $[16,18]$.

The aim of our study was to examine the dependence of reaction time on the moment of inertia of the limbs of participants during adduction of the forearm and hand. In contrast to Anson's [26] study, our research involved a large array of participants of both genders with the same age. This approach offers two advantages; the opportunity to compare the inertial characteristics of a large number of participants, and, to avoid artificial loading of their segments.

\section{METHOD}

\section{Participants}

Five hundred and sixty six healthy students from 50 Moscow high schools ( 274 boys and 292 girls; aged 16-17 years) were involved in the study. None of the participants had outstanding athletic achievements. This age was selected because by this time the human motor system has mostly matured, especially in terms of anthropometrical maturation of the segments of the upper extremities [29]. According to a simplified laterality quotient test [30] all participants were considered to be right-handed, which is important for all researchers studying reaction time $[31,32]$. All participants were at similar levels of scholastic study. The experiments were undertaken during the first half of the day. Before the experiment, each participant was acquainted with the objectives of the experiment and signed an ethical protocol.

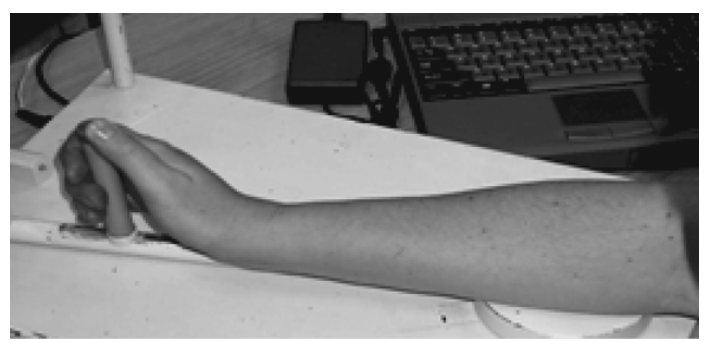

View of the experiment.

\section{Measurement of Basic Anthropometric Parameters}

Standard anthropometrical methods for measuring height and body mass were used (with accuracy \pm 0.5 $\mathrm{cm}$ and $\pm 0.1 \mathrm{~kg}$ respectively). Calculations of moments of rotational inertia used well known regression equations, separately for hand and forearm [3336]. Afterward these data were averaged. Also, we measured the greatest and smallest circumferences of both forearms as well as their length from acromion to styloid process, as recommended [37]. Because the regression tables for calculation of rotational inertia (see below) were unilateral we used only the participants with negligible variation between left and right sides (less than $0.5 \mathrm{~cm}$ ).

\section{The Main Experiment}

Measurement of RT was conducted under standard experimental conditions [8, 31, 38-40 and others]. The study of the latent period of simple sensor-motor reaction was performed using a specific instrument called a computer movement meter ("KMM") produced by the company INTOKS (St. Petersburg), Registration Certificate Number 29/03041202/508503 April 11, 2003. The accuracy of the time measurement of the simple sensor-motor reaction was $1 \mathrm{~ms}$, as used by other researchers $[39,41]$.

\section{PROCEDURE}

The participant was seated in a comfortable chair, while his/her hand rested on a special handle and lever, which, in turn, was able to revolve around a vertical axis. The fulcrum of the rotating segment was treated as the upper third of the forearm. In this position the forearm and wrist could perform abduction and adduction (see figure).

Mechanical resistance to rotational movement of the forearm was negligible and therefore ignored in the calculations. Initially, the lever with forearm and wrist resting on it was fixed on the zero position by electromagnetic arresters. Participants were instructed to focus on a cross in the centre of the screen, and to adduct the handle of the lever with their forearm and wrist as quickly as possible in response to visual signals started at random intervals ( $4-8$ seconds) as previ- 
Table 1. The results of rotational inertia and reaction time $\sigma$-standard deviation

\begin{tabular}{l|c|c|c|c}
\hline \multicolumn{1}{c|}{ Participants } & Total group & Subgroup A & Subgroup B & Subgroup C \\
\hline Males & $n=274$ & $n=143$ & $n=62$ & $n=69$ \\
\hline $\mathrm{RI}_{\text {Average }}\left(\mathrm{kg} \mathrm{cm}^{2}\right)$ & $67.61 \pm 14.15$ & $67.35 \pm 9.46$ & $81.98 \pm 14.09$ & $54.68 \pm 8.98$ \\
$\mathrm{RT}_{\text {Average }}(\mathrm{ms})$ & $0.153 \pm 0.036$ & $0.151 \pm 0.028$ & $0.169 \pm 0.048$ & $0.140 \pm 0.029$ \\
\hline \multicolumn{1}{c|}{ Females } & $n=292$ & $n=129$ & $n=69$ & $n=94$ \\
\hline $\mathrm{RI}_{\text {Average }}\left(\mathrm{kg} \mathrm{cm}{ }^{2}\right)$ & $54.30 \pm 9.91$ & $54.60 \pm 7.26$ & $64.47 \pm 9.08$ & $46.23 \pm 5.90$ \\
$\mathrm{RT}_{\text {Average }}(\mathrm{ms})$ & $0.162 \pm 0.034$ & $0.160 \pm 0.032$ & $0.181 \pm 0.039$ & $0.149 \pm 0.026$ \\
\hline
\end{tabular}

ously recommended [40]. The visual signals (vivid light) were slightly peripheral to the central visual field, in order to potentially speed up sensor-motor reaction [38]. At the instant the light was switched on the electromagnetic arresters were simultaneously deactivated and the lever was able to move freely.

The latent period of the motor response, reaction time, was measured from the moment the light was switched on until the angular displacement of the forearm and lever was one degree as recorded by a computer. The participants were not limited in the possible amplitude of translation of the lever. The study was performed for both dominant and subdominant hands. Each participant produced 16 signal evoked reactions with each hand. Training before the experiment included reaction for 10 visual stimuli which were randomly distributed in time. Experiments in which the participant began to move the lever before appearance of the stimulus, as well as the first three and last three values of reaction time were excluded from the total data set. The total number of experiments was 11.320 (566 participants $\times(26-6)$ stimuli). Time of presentation of each consequent signal ranged from 4 to 10 seconds to avoid the formation of a conditioned reflex to time.

\section{Analysis}

Treatment of the primary data. The total value of the rotational inertia (RI), of the hand and forearm was calculated for each participant. Then the average value $\left(\mathrm{RI}_{\text {average }}\right)$ and standard deviation (a) were calculated, separately for groups of girls and boys. Lateral differences in the upper extremities during the RT test were not significant $(\mathrm{P}>0.05)$ and hence we united the data performed by dominant and subdominant hands in each group. Thus we studied two groups of people: males and females. Based on the results of the calculation of the group average and individual data of rotational inertia the male and female participants were divided into three subgroups. Subgroups of the males were: A) with the middle individual values of rotational inertia: $\mathrm{Rl}_{\text {Middle }}=\mathrm{RI}_{\text {average }} \pm 0.5 \sigma=60.54-$ $74.69 \mathrm{~kg} \mathrm{~cm}^{2}$; B) with high values - $\mathrm{R}_{\text {high }}>\mathrm{RI}_{\text {average }}+$ $0.5 \sigma$, i.e. $>74.69 \mathrm{~kg} \mathrm{~cm}^{2}$; and, C) with low values
$\mathrm{RI}_{\text {low }}<\mathrm{RI}_{\text {average }}-0.5 \sigma$, i.e $<60.54 \mathrm{kgc} \mathrm{m}^{2}$ of rotational inertia. The female subgroups were, correspondingly: A) $49.34-59.25 \mathrm{kgc} \mathrm{m}^{2}$; B) > 59.25 $\mathrm{kg} \mathrm{cm}^{2}$; and C) < $49.34 \mathrm{~kg} \mathrm{~cm}^{2}$. Thus 6 subgroups were formed. Then, for each selected subgroup the appropriate range of RT was identified and mean values of the latent period were calculated (for subgroup A, $\mathrm{RT}_{\text {average }} \mathrm{A}$; for subgroup $\mathrm{B}, \mathrm{RT}_{\text {average }} \mathrm{B}$; for subgroup $\mathrm{C}, \mathrm{RT}_{\text {average }} \mathrm{C}$ ).

Statistical calculations were used to test and compare between the student's groups. The Chi-square method was used for comparison of frequency distribution of particular ranges of latency periods in different subgroups. In addition the point bisserial coefficient of correlation was calculated. The full range of reaction time data (separately for boys and girls) was divided into seven intervals. Interval 1 includes the results of RT below $125 \mathrm{~ms}$; interval 2, from 126 to $150 \mathrm{~ms}$; interval 3, from 151 to $175 \mathrm{~ms}$; interval 4, from 176 to $200 \mathrm{~ms}$; interval 5, from 201 to $225 \mathrm{~ms}$; interval 6, from 226 to $250 \mathrm{~ms}$; and interval 7, more than $250 \mathrm{~ms}$. The Chi square test was used to compare the distribution between selected subgroups of males and females and also between equivalent subgroups of males and females.

\section{RESULTS}

The main results of the research are presented in Tables 1 and 2. It was established that the average value of rotational inertia of the total group of young males, was significantly higher than that of the females $(\mathrm{P}<0.001)$ (see Table 2).

It was found that the RT strongly depended on the selected group. The highest values of RT occurred in subgroup B, the lowest in subgroup C (See Table 1). This pattern was apparent in both male and female groups. The differences between subgroups $\mathrm{B}$ and $\mathrm{C}$, with high and low magnitude of rotational inertia respectively, were significant (up to $17.16 \%$ in male and $17.68 \%$ in female groups; $\mathrm{P}<0.001$ ) (see Table 2). Using the Chi square test we found significant differences in distribution of reaction times produced by equivalent male and female subgroups (See Table 4).

In both male and female groups we found significant differences in distributions of RT data between all 
Table 2. Comparison between different groups and subgroups, $t$ value and probability $(\mathrm{P})$

\begin{tabular}{|c|c|c|c|c|}
\hline Participants & Groups & $t$ value & $p$ & Difference $\%$ \\
\hline \multirow{10}{*}{$\begin{array}{l}\text { Comparison between male } \\
\text { and female groups }\end{array}$} & \multicolumn{4}{|c|}{ Rotational inertia } \\
\hline & Total groups & 12.85 & 0.0001 & 19.69 \\
\hline & A subgroups & 12.51 & 0.0001 & 18.93 \\
\hline & B subgroups & 8.46 & 0.0001 & 21.36 \\
\hline & C subgroups & 6.70 & 0.0001 & 15.45 \\
\hline & \multicolumn{4}{|c|}{ Reaction time } \\
\hline & Total groups & 3.099 & 0.002 & 5.88 \\
\hline & A subgroups & 2.936 & 0.0036 & 5.96 \\
\hline & B subgroups & 1.56 & 0.12 & 7.1 \\
\hline & C subgroups & 2.017 & 0.045 & 6.43 \\
\hline \multirow{8}{*}{$\begin{array}{l}\text { Comparison between male } \\
\text { subgroups }\end{array}$} & \multicolumn{4}{|c|}{ Rotational inertia } \\
\hline & $\mathrm{A}$ and $\mathrm{B}$ & 8.304 & 0.0001 & 21.72 \\
\hline & A and $C$ & 9.23 & 0.0001 & 18.81 \\
\hline & $\mathrm{B}$ and $\mathrm{C}$ & 12.68 & 0.00001 & 33.30 \\
\hline & \multicolumn{4}{|c|}{ Reaction time } \\
\hline & $\mathrm{A}$ and $\mathrm{B}$ & 4.38 & 0.001 & 10.65 \\
\hline & A and $\mathrm{C}$ & 2.44 & 0.011 & 7.28 \\
\hline & $\mathrm{B}$ and $\mathrm{C}$ & 5.92 & 0.0001 & 17.16 \\
\hline \multirow{8}{*}{$\begin{array}{l}\text { Comparison between female } \\
\text { subgroups }\end{array}$} & \multicolumn{4}{|c|}{ Rotational inertia } \\
\hline & $A$ and $B$ & 9.33 & 0.0001 & 14.65 \\
\hline & A and $C$ & 9.78 & 0.0001 & 12.43 \\
\hline & $\mathrm{B}$ and $\mathrm{C}$ & 12.46 & 0.0001 & 28.29 \\
\hline & \multicolumn{4}{|c|}{ Reaction time } \\
\hline & $A$ and $B$ & 4.23 & 0.0011 & 11.60 \\
\hline & A and $C$ & 4.15 & 0.001 & 6.88 \\
\hline & $\mathrm{B}$ and $\mathrm{C}$ & 7.45 & 0.0001 & 17.68 \\
\hline
\end{tabular}

Table 3. Distribution of RT in selected intervals (in \%)

\begin{tabular}{l|r|r|r|r|r|r|r|r|r}
\hline \multicolumn{1}{c}{ RT (ms) } & $<125$ & $126-150$ & $151-175$ & $176-200$ & $201-225$ & $226-250$ & $251>$ \\
\hline \multicolumn{7}{c}{ Males } \\
A subgroups & 18.88 & 30.77 & 32.17 & 12.59 & 4.90 & 0.00 & 0.70 \\
B subgroups & 6.45 & 33.87 & 27.42 & 11.29 & 9.68 & 6.45 & 4.84 \\
C subgroups & 33.33 & 30.43 & 24.64 & 10.14 & 0.00 & 0.00 & 1.45 \\
\multicolumn{7}{|c|}{ Females } \\
A subgroups & 13.18 & 27.13 & 25.58 & 21.71 & 10.85 & 0.78 & 0.78 \\
B subgroups & 2.90 & 20.29 & 28.99 & 17.39 & 15.94 & 10.14 & 4.35 \\
C subgroups & 19.15 & 37.23 & 27.66 & 12.77 & 3.19 & 0.00 & 0.00 \\
\hline
\end{tabular}

subgroups A, B and C (see Tables 3 and 4). There was a marked difference in the number of participants in different subgroups reacting to visual stimuli very quickly and very slowly, as is illustrated in Table 3; $33.33 \%$ males and $19.15 \%$ females from group C reacted in a very fast way with RT less than $125 \mathrm{~ms}$. Participants from group B demonstrated very delayed reaction times; $21 \%$ males and $30.4 \%$ females demonstrated reaction time more than $200 \mathrm{~ms}$ (see Table 3 ). The male and female participants of subgroup B have

HUMAN PHYSIOLOGY Vol. $40 \quad$ No. 22014 
Table 4. Difference in distribution; values of $\chi^{2}$ and probability (P)

\begin{tabular}{l|c|c|c|c|c}
\hline & $\begin{array}{c}\text { Between all three } \\
\text { subgroups of males }\end{array}$ & $\begin{array}{c}\text { Between all three } \\
\text { subgroups of females }\end{array}$ & $\begin{array}{c}\text { Between Males } \\
\text { and Females } \\
\text { in subgroup A }\end{array}$ & $\begin{array}{c}\text { Between Males } \\
\text { and Females } \\
\text { in subgroup B }\end{array}$ & $\begin{array}{c}\text { Between Males } \\
\text { and Females } \\
\text { in subgroup C }\end{array}$ \\
\hline$\chi^{2}$ & 234 & 342 & 191 & 62 & 89 \\
$p$ & $<0.0001$ & $<0.0001$ & $<0.0001$ & $<0.0001$ & $<0.0001$ \\
\hline
\end{tabular}

different RT modal intervals; $0.126-0.150 \mathrm{~ms}$ and $0.151-0.175 \mathrm{~ms}$ respectively.

The relationship between subgroups containing people with different values of rotational inertia and their produced RT data was indicated by the value of point-bisserial correlation coefficients which were; 0.58 (comparing subgroups A and B), 0.46 (between subgroups $A$ and $C$ ), and 0.72 (comparing subgroups B and C).

\section{DISCUSSION}

The main objective of this research was to examine a relationship between time of simple motor reaction and magnitude of rotational inertia of the reacting segment, which may partly represent the integrative morphometric features of the human body. As was mentioned previously all our participants were recruited from 50 Moscow high schools, with approximately the same learning and physical environment.

Our results of RT are close to the results received by other authors for young healthy individuals [2, 41, 42]. This outcome indicates the validity of the chosen method of researching the latent period.

We united the data of RT of both hands in one pool because we did not record significant group differences in total RT between left and right-sided actions. This finding can be explained by the fact that this motor response involved relatively proximal segments of upper extremities, whose muscles have bilateral innervations, from both the left and right hemispheres [43-45]. Three subgroups were selected within male and female groups on the basis of the values of their rotational inertia: one subgroup (A) with the middle range of $\mathrm{RI}$,

others with high $(\mathrm{B})$ and low $(\mathrm{C})$ ranges of $\mathrm{RI}$. The same approach was used in our recent work [27].

We tested the hypothesis that greater values of rotational inertia increase RT. The fact that participants having higher indices of rotational inertia of forearm and wrist reacted more slowly can be explained by the influence of inertial forces impeding the rotational acceleration of the hands (forearms and hands) at the beginning the movement. In our case, the participant had to make a very brief adduction around the vertical axis passing through the elbow of the participant.

It is well known that the latency period of simple sensor motor reactions is based on perceptual functions, decision making and motor performance [40,
46-48] and also depends upon the kinetic and kinematic properties of reacting segments [11, 14, 34]. Since in our case, the participants were focused only on rapid movement in a predetermined direction where no accuracy was required we can suggest a low level of complexity for this kind of motor reaction. This kind of movement requires more primitive programs that significantly reduce the time of decision making. Thus we restricted the scope of our research to find out the influence of the value of rotational inertia of segments on reaction time. The conditions of the experiment were extremely simplified to avoid complexity of reactions [40, 46-48]. During the experiment participants adducted their forearms over a very short distance in a constant direction. In other words, the realized motor reaction in our case appeared as a short jerk without any additional precise component. We classify this motion as a jerk because it was organized mainly by only one, relatively weak pronator teres muscle [49], was lasting a very short time and had the aim to shift the essential mass of the segment. For this kind of reaction the role of inertial resistive forces became more influential. For this purpose, the central nervous system in a short period of time had to implement the recruitment of a large number of fibers of the muscle. If the segment had a greater mass and consequently greater rotational inertia, the recruitment of a greater number of muscle fibers required a longer period of time.

Longer RT may be due to an additional period needed for increasing the number of active motor units and increasing their firing rate to optimize the tension generated, that is, spatial and temporal recruitment [25].

Results of other authors also support our hypothesis about influences of RI or its derivatives increasing reaction time [27, 46]. Many authors have reported longer periods of sensor-motor reactions in cases of activation of heavier or longer segments [14, 16-24]. The NASA [50] report states that the time required to move an object in microgravity increases as the mass of the object increases. According to another point of view, if mechanical or shape aspects of any regulated segment are changed, then behavioral interpretation of muscular activity accountable for the reaction must also be changed [12, 13]. Eckner and colleagues [51] reported that the reaction times of football players averaged $0.203 \mathrm{~s}$ when determined with a simple falling meter stick, but was $0.268 \mathrm{~s}$ when measured with a 
computer, probably because the reacting segment had a different mass.

It was interesting that the pattern of relationship between RI and RT appeared separately within male and female groups but did not appear in comparison between males and females. As we can see males in different subgroups had greater RI indices; why in this case did females not react faster than males and why was the duration of the latent period in females significantly higher compared to equivalent groups of males?

It is known from the literature that males have faster reaction times than females, and this feature is not altered by training [32, 42, 52-54]. The male advantage in terms of shorter RT is also greater when using visual stimuli [55]. In our case, this relationship manifested only in relation to subgroups $A$ and $C$, and did not appear in group B, while Group B of the girls reacted more slowly in terms of the data presented only in the modal interval. We suggest that it could be due to the difference in specific physiological and morphometrical organization of muscle systems in both genders. Males in the end of puberty have greater power output of skeletal muscles, and greater percentage of fast twitch fibers than females [56]. Thus males, even with a greater RI of the reacting segment initially, have greater muscle power to get this segment to react.

Our results indicate that rotational inertia is an important biomechanical characteristic of reacting upper extremities of participants and provides an essential component of reaction time. Rotational inertia should be considered when determining the latent period of sensor-motor reactions under different conditions.

\section{CONCLUSIONS}

1. A significant factor influencing reaction time is rotational inertia of the reacting segment. Individuals with high RI have a significant delay in RT in comparison to persons having low RI values. This dependence was observed equally in males and females.

2. The fact that males had a shorter latent period than females can be explained by the fact that the power of their muscles, which move the reacting segments, is greater.

3. In all investigations which study RT the individual value of RI should be considered.

The role of RI increases markedly in cases where it is necessary to compare RT of participants that belong to different somatic groups.

\section{ACKNOWLEDGMENTS}

This article reports on the project: "Development of technology for health assessment using populationbased software of multi systemic research, no. 0120.0 851867" performed by the Scientific Research Insti- tute of General Pathology and Physiopathology, Russian Academy of Medical Science.

\section{REFERENCES}

1. Bernstein, N.A., The Coordination and Regulation of Movement, Oxford, UK: Pergamon, 1967.

2. Brebner, J.T. and Welford, A.T., Introduction: an historical background sketch, in Reaction Times, Welford, A.T., Ed., New York: Academic Press, 1980, pp. $1-23$.

3. Hatzitaki, V., Zisi, I., Kollias, E., and Kioumourtzoglou, V., Perceptual-motor contributions to static and dynamic balance control in children, Journal of Motor Behavior, 2002, vol. 34, no. 2, pp. 161-170.

4. Kolb, B. and Whishaw, J.Q., Human Neuropsychology, New York: Worth Publishers, 1995.

5. Botwinick, J. and Thompson, L.W., Premotor and motor components of reaction time, Journal of Experimental Psychology, 1966, vol. 71, nos. 9-15.

6. Gold, J.I. and Shadlen, M.N., The neural basis of decision making, Annual. Review of Neuroscience, 2007, vol. 30, pp. 535-574.

7. Rozenbaum, D.A., Human Movement Control, 2nd ed., Boston, MA: Elsevier Academic Press, 2010.

8. Schmidt, R.A., Motor Control and Learning: A Behavioral Emphasis, Champaign, IL: Human Kinetics, 1982.

9. Davis, R.C., Set and Muscular Tension, Indiana University Publications, Science Series, 1940, no. 10.

10. Jiménez-Jiménez, F.J., Calleja, M., Alonso-Navarro, H., Rubio, L., Navacerrada, F., Pilo-de-la-Fuente, B., Plaza-Nieto, J.F., Arroyo-Solera, M., GarcIa-Ruiz, P.J., García-Martin, E., and Agündez, J.A., Influence of age and gender in motor performance in healthy subjects, Neurological Science, 2011, vol. 302, nos. 1-2, pp. 7280 .

11. Enoka, R., Neuromechanical Basis of Kinesiology, 1 Champaign, IL: Human Kinetics, 1994.

12. Loeb, G.E., Motoneurone task groups: Coping with kinematic heterogeneity, Journal of Experimental Biology, 1985, vol. 115, pp. 137-146.

13. Murray, W.M., Delp, S.L., and Buchanan, T.S., Variation of muscle moment arms with elbow and forearm position, Journal of Biomechanics, 1995, vol. 28, pp. 513-525.

14. Chu, N.-S., Motor evoked potentials with magnetic stimulation: Correlations with height, Electroencephalography and Clinical Neurophysiology/Evoked Potentials Section, 1989, vol. 74, no. 6, pp. 481-485.

15. Gutnik, B.J., Mackie, H.W., Guo, W., and Nicholson, J., Lateral difference in reaction times to lateralized auditory stimuli, Indian Journal of Physiology and Pharmacology, 2001, vol. 45, no. 1, pp. 63-70.

16. Mignardot, J.B., Olivier, I., Promayon, E., and Nougier, V., Obesity impact on the attentional cost for controlling posture, PLoS One, 2010, vol. 5, no. 12, p. 14387.

17. Samaras, T.T., Bartke, A., and Rollo, C.D., Human Body Size and the Laws of Scaling: Physiological, Perfor- 
mance, Growth, Longevity and Ecological Ramifications, New York: Nova Publishers, 2007.

18. Williams, H.G., Pfeiffer, K.A., O’Neill, J.R., Dowda, M., Mclver, K.L., Brown, W.H., and Pate, R.R., Motor skill performance and physical activity in preschool children, Obesity, 2008, vol. 16, pp. 14211426.

19. Čoh, M., Tomažin, K., and Štuhec, S., The biomechanical model of the sprint start and block acceleration, Facta Universitatis Series: Physical Education and Sport, 2006, vol. 4, no. 2, pp. 103-114.

20. Čoh, M., Peharec, S., and Bačic, P., The sprint start: biomechanical analysis of kinematic, dynamic and electromyographic parameters, New Studies in Athletics. $I A A F, 2007$, vol. 22, no. 3, pp. 29-38.

21. Collet, C., Strategic aspects of reaction time in worldclass sprinters, Perceptual and Motor Skills, 1999, vol. 88 , pp. 65-75.

22. Mero, A. and Komi, P.V., Reaction time and electromyographic activity during a sprint start, European Journal of Applied Physiology, 1990, vol. 61, pp. 73-80.

23. Mero, A., Komi, P.V., and Gregor, R.J., Biomechanics of sprint running, Sports Medicine, 1992, vol. 13, no. 6, pp. 376-392.

24. Pain, M.T.G. and Hibbs, A., Sprint starts and the minimum auditory reaction time, Journal of Sports Sciences, 2007, vol. 25, pp. 79-86.

25. Lieber, R.L., Skeletal Muscle, Structure, Function and Plasticity. The Physiological Basis of Rehabilitation, Philadelphia: Lippincott Williams \& Wilkins, 2002.

26. Anson, J.G., Effects of moment of inertia on simple reaction time, Journal of Motor Behavior, 1989, vol. 21, no. 1 , pp. 60-71.

27. Skurvydas, A., Gutnik, B., Zuoza, A.K., Nash, D., Zuoziene, I.J., and Mickeviciene, D., Relationship between simple reaction time and body mass index, Homo, 2009, vol. 60, no. 1, pp. 77-85.

28. Spirduso, W.W., Reaction and movement time as a function of age and physical activity level, Journal of Gerontology, 1975, vol. 30, no. 4, pp. 435-440.

29. Malina, R.M. and Johnston, F.E., Relation between bone, muscle, and fat widths in the upper arms and calves of boys and girls studied cross-sectionally at ages 6 to 16 years, Human Biology, 1967, vol. 39, pp. 211223.

30. Oldfield, R.C., The assessment and analysis of handedness: the Edinburgh inventory, Neuropsychologia, 1971, vol. 9, no. 1, pp. 97-113.

31. Barthélémy, S. and Boulinguez, P., Manual reaction time asymmetries in human subjects: the role of movement planning and attention, Neuroscience Letters, 2001, vol. 315, no. 1, pp. 41-44.

32. Dane, S. and Erzurumluoglu, A., Sex and handedness differences in eye-hand visual reaction times in handball players, International Journal of Neuroscience, 2003, vol. 113, no. 7, pp. 923-929.

33. Bouisset, S. and Pertuzon, I., Experimental determination of the moment of inertia of limb segments, in Biomechanics 1, 1st International Seminar (Zurich, 1967), Wartenwiler, J., Ed., Basel, New York: Karger, 1968, pp. 106-109.
34. Chaffin, D.B., Andersson, G.B J., and Martin, B.J., Occupational Biomechanics, 3rd ed., New York: J. Wiley \& Sons, 1999.

35. McConville, J.T., Churchill, T.D., Kaleps, I., Clauser, C.E., and Cuzzi, J., Anthropometric relationships of body and body segment moments of inertia, AFAMRL-TR-80-119, Wright-Patterson Air Force Base, OH, 1980.

36. Zatsiorsky, V.M. and Seluyanov, V.N., The mass and inertia characteristics of the main segments of the human body, in Biomechanics VIII-B, Matsui, H. and Kobayashi, K., Eds., Champaign, IL: Human Kinetics Publishers, 1983, pp. 1152-1159.

37. Malina, R.M. and Buschang, P.H., Anthropometric asymmetry in normal and mentally retarded males, Annals of Human Biology, 1984, vol. 11, no. 6, pp. 515531.

38. Ando, S., Kida, N., and Oda, S., Practice effects on reaction time for peripheral and central visual fields, Perceptual and Motor Skills, 2002, vol. 95, no. 3, pp. 747-752.

39. Kosinski, B. and Cummings, J., The scientific method: An introduction using reaction time, in Tested Studies for Laboratory Teaching, vol. 25, O'Donnell, M.A., Ed., Proceedings of the 25th Workshop/Conference of the Association for Biology Laboratory Education (ABLE), 2004, pp. 219-234.

40. Schmidt, R.A. and Lee, T.D., Motor Control and Learning: A'behavioral Emphasis, 3rd ed., Champaign, IL: Human Kinetics. 1999.

41. Parekh, N., Gajbhiye, I.P.R., Wahane, M., and Titus, J., The study of auditory and visual reaction time in healthy controls, Journal, Indian Academy of Clinical Medicine, 2004, vol. 5, no. 3, pp. 239-43.

42. Welford, A.T., Choice reaction time: Basic concepts, in Reaction Times, Welford, A.T., Ed., New York: Academic Press, 1980, pp. 73-128.

43. Brinkman, J. and Kuypers, H.G.J.M., Split-brain monkeys: Cerebral control of

ipsilateral and contralateral arm, hand and finger movements, Science, 1972, vol. 176, pp. 536-539.

44. Di Stephano, M., Morelli, M., Marzi, C., and Berlucchi, G., Hemispheric control of unilateral and bilateral movements of proximal and distal parts of the arms inferred from simple reaction time to the lateralized light stimuli in man, Experimental Brain Research, 1980, vol. 38, pp. 197-204.

45. Gazzaniga, M.S., The Bisected Brain, New York: Appleton-Century Crofts, 1970.

46. Anson, J.G., Memory drum theory: Alternative tests and explanations for the complexity effects on simple reaction time, Journal of Motor Behavior, 1982, vol. 14, no. 3, pp. 228-246.

47. Christina, R.W., Fischman, M.G., and Vercruyssen, M.J., Simple reaction time as a function of response complexity: memory drum theory revisited, Journal of Motor Behavior, 1982, vol. 14, no. 4, pp. 301-321.

48. Margill, R.A., Motor Learning (Concepts and Applications), International edition, Boston, Mass.: Mc-Graw Hill, 1988. 
149. Neumann, D.A., Kinesiology of the Musculoskeletal System: Foundations for Rehabilitation, 2nd ed., Missouri: Mosby/Elsevier, 2010.

50. NASA-STD-3000. 196, 1995, vol. 1, sec. 4.7, pp. 1-90, reference 171 and 347.

2 51. Eckner, J.T., Kutcher, J.S., and Richardson, J.K., Pilot evaluation of a novel clinical test of reaction time in National Collegiate Athletic Association Division I football players, Journal of Athletic Training, 2010, vol. 45, no. 4, pp. 327-333.

52. Adam, J.J., Paas, F.G., Buekers, M.J. Wuyts, I.J.,

3 Spijkers, W.A., and Wallmeyer, P., Gender differences in choice reaction time: evidence for differential strategies, Ergonomics, 1999, vol. 42, no. 2, pp. 327-335.

53. Der, G. and Deary, I.J., Age and sex differences in reaction time in adulthood: results from the United King- dom Health and Lifestyle Survey, Psychology and Aging, 2006, vol. 21,no. 1, pp. 62-73.

54. Noble, C., Baker, B.L., and Jones, T.A., Age and sex parameters in psychomotor learning, Perceptual and Motor Skills, 1964, vol. 19, pp. 935-945.

55. Spierer, D.K., Petersen, R.A., Duffy, K., Corcoran, B.M., and Rawls-Martin, T., Gender influence on response time to sensory stimuli, Journal of Strength and Conditioning Research, 2010, vol. 24, no. 4, pp. 957-963.

56. Temfemo, A., Hugues, J., Chardon, K., Mandengue, S.H., and Ahmaidi, S., Relationship between vertical jumping performance and anthropometric characteristics during growth in boys and girls, European Journal of Pediatrics, 2009, vol. 168, no. 4, pp. 457-464.

SPELL: 1. Kinesiology, 2. Kutcher, 3. Spijkers

HUMAN PHYSIOLOGY Vol. $40 \quad$ No. 22014 